\title{
SEASONAL ABUNDANCE OF HORSE FLIES (DIPTERA, TABANIDAE) IN THE CHIRPAN EMINENCES, BULGARIA
}

\author{
D. Ganeva*, M. Kalmushka \\ Department of Biology and Aquaculture, Faculty of Agriculture, Trakia University, \\ Stara Zagora, Bulgaria
}

\begin{abstract}
The aim of the present study was to explore the seasonal activity of tabanids on the territory of the Chirpan Eminences, in Stara Zagora region, Bulgaria. The study was carried out during the flight period (May - September, 2010 - 2011). A total of 1034 specimens of tabanids from 23 species and 8 genera were collected and identified. The horse flies began flying during the second half of May and its flight period lasted until mid - September. The peak of seasonal abundance was observed during the first half of July. The most abundant species in the horse flies assemblages on the Chirpan Eminences were Tabanus quatuornotatus (35.30\%), Tabanus tergestinus (28.05\%) and Philipomyia graeca (10.93\%). The largest number of specimens of T. tergestinus was collected during the peak of seasonal abundance of horse flies on the territory of the Chirpan Eminences.
\end{abstract}

Key words: seasonal activity, tabanids, dominant species, Chirpan Eminences, Bulgaria.

\section{INTRODUCTION}

Tabanids in Europe were active during the spring to summer period, but their appearance in nature and the duration of their activity period were influenced by their phenological features, the geographic latitude $(1,2)$, the altitude (1, 3-5), the specific complex of meteorological factors and landscape features of each biotope (6-13).

According to (14), in Bulgaria tabanids began flying in early spring. (8) reported about their activity in Stara Zagora region from the beginning of May till almost the end of September with a peak during the first half of July. She has established differences in their appearance not only in the years, but also in the different localities during one and the same year. In her opinion this is due to the fluctuations in the meteorological factors over the years and the landscape characteristics of the biotopes studied (8). (12) mentioned also a

\footnotetext{
*Correspondence to: Diana Ganeva, Department of Biology and Aquaculture, Faculty of Agriculture, Trakia University, Student Campus, 6000 Stara Zagora, Bulgaria; Tel.: (+359) 42699324 , Fax:(+359) 42278066 ; d_ganeva2000@yahoo.com
}

similar dependence in his studies about the seasonal activity of tabanids in Eastern Croatia. The fluctuations in the horse flies seasonal activity established in comparatively close biotopes in Stara Zagora region provoked the interest in studying their activity on the Chirpan Eminences territory (Stara Zagora region, Southern Bulgaria) too. What is more such research has not been carried out there. This study was a part of the research, conducted on the fauna and activity of the horse flies of the Tabanidae family in the Chirpan Eminences. As a result of the study of the tabanid fauna composition in the Chirpan Eminences, (15) reported 28 species and subspecies belonging to 8 genera.

\section{MATERIALS AND METHODS}

The Chirpan hills are located north of the town of Chirpan, in the Upper Thracian lowland. Their northern slopes merge with the sloping southern slopes of Sarnena Sredna Gora Mts. Their relief is hilly, intersected by drylands and valleys of small rivers. The altitude of the Chirpan Eminences varies between 600 - 650 $\mathrm{m}$. The highest peak is Mount Kitka - $652 \mathrm{~m}$. The northern slopes of the Chirpan Eminences are steeper, unlike the southern ones, which 
GANEVA D., et al.

descend gradually towards the valley of the Maritsa River. The Chirpan Eminences fall into the transitional-continental climate region of Bulgaria (16). They are characterized by a milder winter, a lower annual air temperature amplitude, two maximums (July and November) and two minimums (August and February) of precipitations. The valley of the Maritsa river is influenced by the Mediterranean climate, which modifies the climate in the area. The Chirpan hills are included in the list of Protected areas under Directive 92/43/EEC on the Conservation of Natural Habitats and Wild Flora and Fauna, code BG0000628.

The dynamics of the horse flies seasonal activity was studied during from May to September 2010 - 2011 in two localities on the territory of the Chirpan Eminences.

Locality Stoyan Zaimovo (431 m above sea level) is situated $19 \mathrm{~km}$ from the town of Chirpan on the road to the village of Stoyan Zaimovo, the highest point of the road passing through the ridge. On the west side of the road there is a coniferous forest and on the eastern one - a meadow with single shrubs. Observations on the tabanid activity were conducted on this meadow. The slope has a southeastern exposure which provides almost constant daylight sunshine (until $5.00-6.00$ $\mathrm{pm})$.

Locality Spassovo (328 $\mathrm{m}$ above sea level) is situated $1.3 \mathrm{~km}$ north of the village of Spasovo, on the road to the village of Sredno gradishte. The area is hilly (the beginning of the Chirpan Eminences). The biotope where the field collections were carried out is a large and dry meadow. There are orchards and small fields in the area and bushes along the road. The woody vegetation, in the vicinity, is represented by single trees - plums and walnuts.

Tabanids were collected monthly by using a sweep net. The collected materials were processed and determined under laboratory conditions. Identification and nomenclature of the species followed that of (1-2) and (17). During the study 1034 specimens of tabanids were caught, $968 \%$ and $66 \hat{\jmath}$. Up to 1027 specimens were identified to the species, and 7 specimens - to the genus.

The air temperature was measured by a mercury thermometer during the field collections. The list of localities indicates the altitude, the coordinates, the collection dates and the collected specimens from each locality. The altitudes and geographic coordinates are measured by Garmin GPS Navigator Etrex VistaHCx.

\section{List of localities}

1. Stoyan Zaimovo, $431 \mathrm{~m}$, 42.32 N, 25.37 E: 31.05.2010, 33 ; 03.06.2010, 59 q; $\mathbf{0 5 . 0 7 . 2 0 1 0}, 123$; 06.08.2010, 15 q; 30.05.2011, 33 +, 4 ; 04.06.2011, 359 ; 10.07.2011, 199 ㅇ, 56 ; 06.08.2011, 16 ; $\mathbf{1 0 . 0 9 . 2 0 1 1 , ~} 1$ q

2. Spassovo, $328 \mathrm{~m}, 42.28 \mathrm{~N}$, 25.32 E: 31.05.2010, 17 ; 03.06.2010, 7 ; 05.07.2010, 44 क; $\mathbf{0 6 . 0 8 . 2 0 1 0 ,} 3$; 03.06.2011， 5 q; 11.07.2011，29，5 ${ }^{3}$; 08.08.2011, 25 ㅇ, 1 ๙ึ.

\section{RESULTS AND DISCUSSION}

A total of 1034 specimens belonging to 8 genera and 23 species were collected and determined in two localities at the Chirpan Eminences (Table 1). The most abundant species were Tabanus quatuornotatus (35.30\%), Tabanus tergestinus $(28.05 \%)$ and Philipomyia graeca (10.93\%) (Table 1). The tabanids in the Chirpan Eminences began flying at the same time (the second half of May) during the two years of the survey (2010 - 2011), but showed differences in the dynamics of their seasonal activity, not only in different investigated biotopes but also in the same locality.

\section{Seasonal abundance of horse flies in Stoyan Zaimovo locality}

A total of 11 species of tabanids were active at the end of May in the locality of Stoyan Zaimovo. Five of them were registered in May, 2010 and 8 - in May, 2011. Only the species Tabanus quatuornotatus and Philipomyia graeca flew over the two years. The remaining 9 species (T. autumnalis, $T$. bifarius, $T$. tergestinus, T. maculicornis, $H$. ciureai, $H$. distinguenda, Th. tricolor pallidicauda, $H$. pluvialis and $D$. ater) were presented in single specimens, but their appearance in the collection at the end of May marked the beginning of their active flight period in the biotop. The largest number of specimens was reported for Tabanus quatuornotatus (2010/2011) and Philipomyia graeca (2010). These were the most abundant species in the tabanid assemblages of Stoyan Zaimovo locality. Tabanus quatuornotatus was a typical early summer species flying in Stara Zagora region from May to the beginning of August, but with the highest activity in June (8). The high number of the Tabanus quatuornotatus 
population at the end of May and during the two years $(51.51 \%$ in 2010 and $77.77 \%$ in 2011) gives us the reason to believe that the
GANEVA D., et al. tabanids in the region start flying during the second half of May.

Table 1. Species composition and number of collected specimens of tabanids in the region of the Chirpan Eminences (2010-2011)

\begin{tabular}{|c|c|c|c|c|c|c|}
\hline \multirow{3}{*}{\begin{tabular}{|l|}
\multicolumn{1}{|c|}{ Species } \\
$\begin{array}{l}\text { Chrysops caecutiens (Linnaeus, } \\
1758)\end{array}$
\end{tabular}} & \multirow{2}{*}{\multicolumn{2}{|c|}{$\begin{array}{cc}\text { Stoyan } & \text { Zaimovo } \\
2010 & 2011\end{array}$}} & \multicolumn{2}{|c|}{ Spassovo } & \multirow{2}{*}{$\begin{array}{c}\text { Total } \\
\text { specimens }\end{array}$} & \multirow[t]{2}{*}{ RA, \% } \\
\hline & & & 2010 & 011 & & \\
\hline & 1 우 & & & & 1 1우 & 0.09 \\
\hline C. ludens Loew, 1858 & & 19 & & & 1 오 & 0.09 \\
\hline $\begin{array}{l}\text { Atylotus loewianus (Villeneuve, } \\
\text { 1920) }\end{array}$ & 90 & & & & $9+$ & 0.87 \\
\hline $\begin{array}{l}\text { Therioplectes gigas (Herbst, } \\
\text { 1787) }\end{array}$ & & 1 우 & & & 1 우 & 0.09 \\
\hline $\begin{array}{l}\text { Th. tricolor pallidicauda } \\
\text { (Olsufjev, 1937) }\end{array}$ & 1 1ㅇ & 1 1우 & & & 2 2+ & 0.19 \\
\hline $\begin{array}{l}\text { Hybomitra caucasi (Szilady, } \\
\text { 1923) }\end{array}$ & & 1 우 & & & 1 1우 & 0.09 \\
\hline H. ciureai (Séguy, 1937) & 29 & 10 우 & & & $12+$ & 1.16 \\
\hline H. distinguenda (Verrall, 1909) & 79 & 229 & 29 & & 31 우 & 3.00 \\
\hline $\begin{array}{l}\text { Tabanus autumnalis Linnaeus, } \\
1761\end{array}$ & & 4 우 & & & 4 우 & 0.39 \\
\hline T. bifarius Loew, 1858 & $2+$ & & & & 29 & 0.19 \\
\hline T. bromius Linnaeus, 1758 & 29 & $\begin{array}{c}13++ \\
60^{\lambda} \\
\end{array}$ & 10 웅 & $\begin{array}{l}7++ \\
10 \\
\end{array}$ & $32 q+7 \sigma^{\lambda}$ & 3.77 \\
\hline T. exclusus Pandellé, 1883 & 29 & 1 우 & 1 우 & 10 우 & 14 우 & 1.36 \\
\hline T. glaucopis Meigen, 1820 & & 19 & & & 19 & 0.09 \\
\hline $\begin{array}{l}\text { T. maculicornis Zetterstedt, } \\
1842\end{array}$ & $11+$ & 33 + & & 5 우 & $49+$ & 4.74 \\
\hline $\begin{array}{l}\text { T. quatuornotatus Meigen, } \\
1820\end{array}$ & 34우 & $\begin{array}{c}\mathbf{3 1 0} \\
\mathbf{3}^{\dagger}+ \\
\end{array}$ & $\mathbf{1 3}+$ & 5 5ㅇ & $\mathbf{3 6 2} \uparrow+\mathbf{3} \AA$ & 35.30 \\
\hline 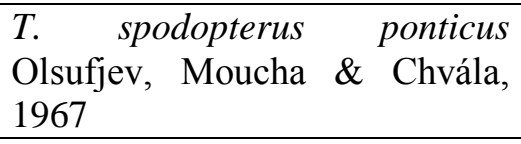 & 1 우 & $\begin{array}{c}15 q+ \\
110^{\lambda}\end{array}$ & & $3 q$ & $19 q+11{ }^{\lambda}$ & 2.90 \\
\hline T. sudeticus Zeller, 1842 & 19 & 3 우 & & 19 & 5 우 & 0.48 \\
\hline T. tergestinus Egger, 1859 & $95+$ & $\begin{array}{c}\mathbf{1 0 5}++ \\
\mathbf{3 8}^{\lambda}+\end{array}$ & $\mathbf{3 4}+$ & $\begin{array}{c}\mathbf{1 4}+{ }_{+}+ \\
4{ }^{\lambda}\end{array}$ & $248+42 \Uparrow$ & 28.05 \\
\hline T. tinctus Walker, 1850 & & 329 & & 119 & 43 우 & 4.16 \\
\hline T. unifasciatus Loew, 1858 & $19+$ & $2+9$ & 19 & $3 q$ & $79+9$ & 0.68 \\
\hline H. pluvialis (Linnaeus, 1758) & 19 & 1 우 & 4 우 & & 69 & 0.58 \\
\hline $\begin{array}{l}\text { Dasyrhamphis ater (Rossi, } \\
\text { 1790) }\end{array}$ & 1 우 & & & & 1 우 & 0.09 \\
\hline $\begin{array}{l}\text { Philipomyia graeca (Fabricius, } \\
\text { 1794) }\end{array}$ & 57 57 & $\begin{array}{c}\mathbf{4 9} \stackrel{+}{+}+ \\
\mathbf{1} \overbrace{}^{\lambda}\end{array}$ & 69 & & $\mathbf{1 1 2}+\mathbf{+ 1} \bigcirc^{\lambda}$ & 10.93 \\
\hline Identified to genus & $2+$ & $\begin{array}{c}3+{ }_{+}^{+} \\
10^{\lambda}\end{array}$ & & $10^{\pi}$ & $5 q+2 \hat{\sigma}$ & 0.68 \\
\hline Total number of specimens & $\mathbf{2 3 0} ㅇ$ & $\begin{array}{l}\mathbf{6 0 8} \bigcirc \\
+60 \hat{O}\end{array}$ & $\mathbf{7 1}+$ & $\begin{array}{c}\mathbf{5 9}+{ }_{+}+ \\
\mathbf{6}\end{array}$ & $968+66 \lambda$ & 99.97 \\
\hline
\end{tabular}

The species Th. gigas, H. caucasi and T. bromius were included in the composition of the horse flies assemblages in June. The Th. gigas and $H$. caucasi were recorded once in the locality with 1 specimen, and the appearance of $T$. bromius in June marked the earliest activation of the species in the locality. The biggest number of specimens of $T$. 
quatuornotatus and Ph.graeca were caught in June (2010/2011) again.

In June activity was reported for 12 species of tabanids. Only 7 of these continued to fly in July. The analysis of phenological data shows that 5 new species (C. caecutiens, $C$. ludens, $T$. spodopterus ponticus, $T$. sudeticus and $T$. tinctus) were included in the tabanid assemblages in July. C.caecutiens was registered only in 2010, Chrysops ludens and Tabanus tinctus only in 2011 and the first appearance of $T$. spodopterus ponticus and $T$. sudeticus occurred in the locality only in July (2010/2011). The dominant species in July (2010/2011) was T. tergestinus. Besides it high activity was also reported for the species: $P h$. graeca (2010); T. bromius, T. spodopterus ponticus and $T$. tinctus (2011) and $T$. maculicornis (2010/2011).

The species $H$. distinguenda $T$. spodopterus ponticus, $T$. tergestinus and $T$. tinctus continued to fly in August. Diversity in the horse flies assemblages in August increased with the late-summer species A. loewianus, $T$. exclusus and $T$. glaucopis, as well as the summer species $T$. unifaciatus. The most abundant species in August were A. loewianus and $T$. tinctus. The remaining species were represented in single specimens.

The latest specimens of tabanids in the studied locality were recorded in the first half of September (10.9.2011). Then, despite the favorable weather conditions (clear, quiet and warm weather, $26^{\circ} \mathrm{C}$ ), there was an extremely low tabanid activity (1 specimen of $T$. exclusus) marking the end of the flight season of the tabanids in the biotope studied.

Thus, on the basis of the monitoring on the seasonal activity of tabanids, it can be concluded that in Stoyan Zaimovo locality the flight activity of tabanids began in the second half of May and ended until the midSeptember.

The analysis of the seasonal activity of horse flies showed that the two flight seasons (MaySeptember, 2010 - 2011) differ in the number of registered species, in the composition of tabanid assemblages during the flight season, in the relative abundance of the established species (Table 1) and in the peak of the seasonal abundance (Figure 1). Regular samplings were conducted almost at one and the same time during each month of the tabanid active period. Therefore, the main reason, in our opinion, for the differences, established in the qualitative and quantitative composition of the tabanid assemblages, was the influence of the specific meteorological conditions in the biotope over the different years.

The comparison between the quantitative indicators (number of specimens caught and number of species) of the field samples revealed that, in 2011 the higher activity of the tabanids was recorded for both quantitative indicators - number of registered species and number of specimens caught (Table 1). However, while during May and August 2010 the tabanid activity was approximately the same (33/36 specimens in May 2010/2011, 14/16 specimens in August 2010/2011), in June and July 2011 a significant increase in flies activity compared to the same period of 2010 (59/357 specimens in June 2010/2011, $122 / 254$ specimens in July 2010/2011) was observed. The meteorological conditions during the field samples on 3 June 2010 was characterized by scattered clouds, unstable wind and a temperature of $20^{\circ} \mathrm{C}$. The catch reported was the result of a collection until noon due to the rainy weather in the afternoon and the temperature drop to $18^{\circ} \mathrm{C}$. The weather was quite different in June 2011. The field collection on 4 June 2011 was carried out in clear and quiet weather throughout the day, with an air temperature between $21-27^{\circ} \mathrm{C}$ (the minimum and the maximum for the day in the biotope) and a wet soil as a result from the precipitations during the previous days. Under these favorable meteorological conditions the maximum of the flight activity (357 specimens in 2011) was recorded for both the respective flight season (Figure 1) and the entire period of the study in Stoyan Zaimovo locality (Figure 2).

July collections were carried out in quiet weather, with scattered clouds and a temperature of, respectively, $29-31^{\circ} \mathrm{C}$ (5.7.2010) and $29-36^{\circ} \mathrm{C}$ (10.7.2011). 122 specimens were captured on July 5, 2010 and 254 specimens were collected on July 10, 2011. The data show that the activity in 2011 was twice as high as in 2010, but from seasonal point of view, a peak of the seasonal abundance was recorded in July 2010, while in July 2011 there was a significant decrease (Figure 1). The decrease in the tabanid activity in July 2011 is explained by the high daily temperature (over $32^{\circ} \mathrm{C}$ at noon), which acts as an inhibitor on the activity of these bloodsucking flies, although tabanid activity was 
observed (although significantly weaker) even at $36^{\circ} \mathrm{C}$.

The seasonal activity in August 2010/2011 (Figure 1) was even lower. Observations were conducted at the same time - on August, 6, 2010/2011 in similar weather: cloudy with clearing at noon, with almost constant light wind and a temperature of, respectively, 24 $28^{\circ} \mathrm{C}(2010)$ and $21-25^{\circ} \mathrm{C}(2011)$. Despite the appropriate flight conditions, the horse flies were recorded only at noon hours at the maximum temperature values. This also reflected on the reported number, respectively, 14 specimens in August 2010 and 16 in 2011.
GANEVA D., et al. The fluctuations in the values of the meteorological factors during the two years and their specific occurrence in the biotopes not only at the time of collections, but also throughout the flight season, are the main reason that influences the dynamics of the tabanid seasonal activity. The scarce precipitations in July $2011(23.8 \mathrm{~mm}$, according to the Meteorological Station, Chirpan) and the lower average daily temperatures in August of the same year $\left(24^{\circ} \mathrm{C}\right)$ slow down the emergence of the late summer species and reduce their flight activity, which reflected on the total registered number.

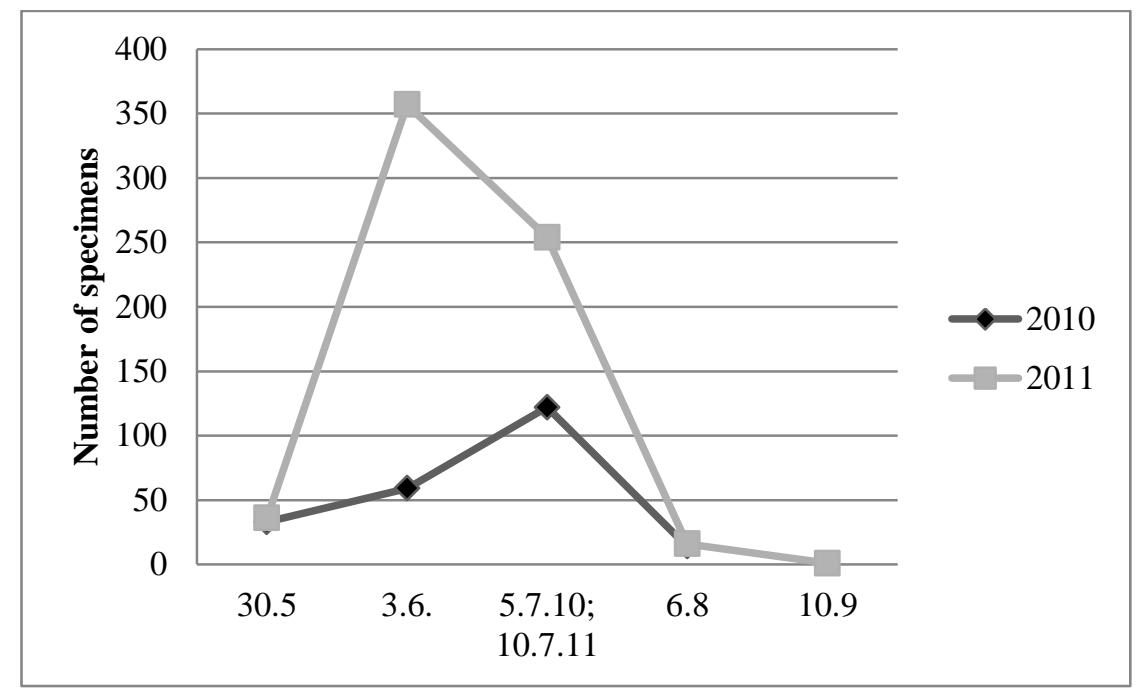

Figure 1. Seasonal abundance of tabanids in the locality Stoyan Zaimovo (2010-2011)

From a seasonal point of view the dynamics of tabanid activity in the studied biotope has a different character during the two flight seasons of the tabanids. The peak of the seasonal abundance in 2010 was at the beginning of July (5.7.) and in 2011- at the beginning of June (4.6) (Figure 1). These differences in the maximum activity affected the general character of the curve for this locality (Figure 2). It was characterized by a less pronounced peak in early June, due to the relatively high activity of tabanids almost until mid-July, after which a sharp drop in their number was recorded in August (Figure 2).

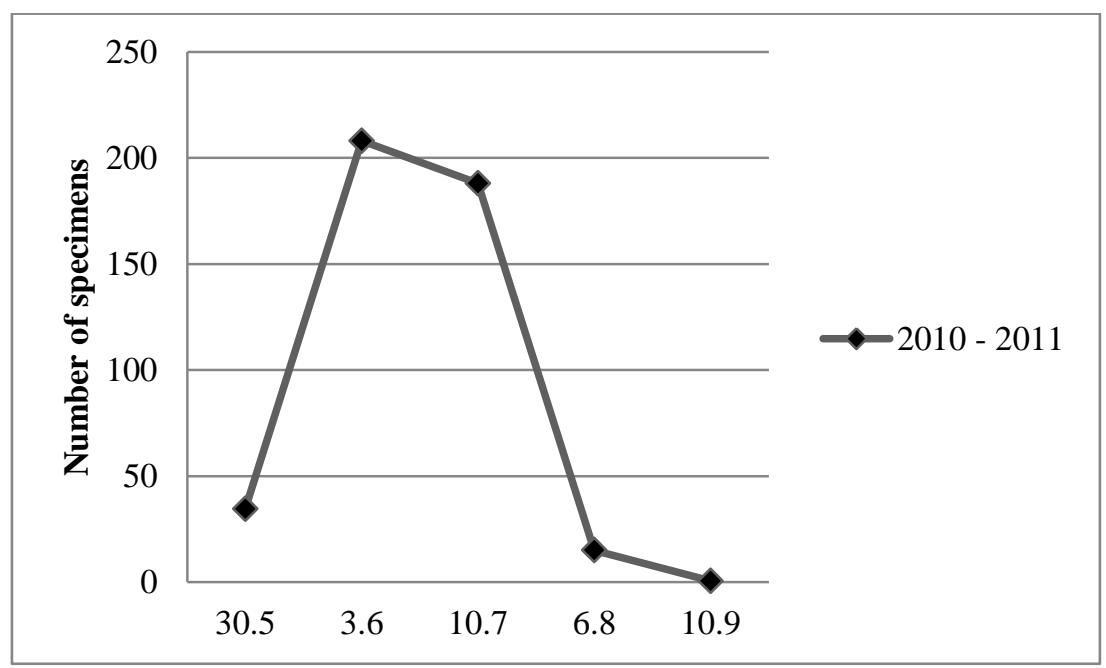

Figure 2. Seasonal abundance of tabanids in the locality Stoyan Zaimovo (average data) 
T. tergestinus was the major participant in the peak formation in 2010 and T. quatuornotatus was the major participant in the peak formation in 2011. T. tergestinus reached the peak in its seasonal abundance in the first half of July in Stoyan Zaimovo locality. These results correspond to the data indicated by (8) and (12) about the peak in the seasonal abundance of T. tergestinus. Regarding T. quatuornotatus, (8) reported a peak in its seasonal abundance around mid-June and we recorded a pronounced peak at the beginning of June in the biotope near Stoyan Zaimovo. (10) also established a peak in the seasonal abundance of T. quatuornotatus in June.

A slighter activity during the peak in their seasonal abundance for 2010 (early July) was found for the third most abundant species in the biotope - Ph.graeca and a subdominant $T$. maculicornis. Phenologically, Ph.graeca is a summer species with a peak of seasonal abundance in Stara Zagora region at the end of June (8). In our observations we established that Ph.graeca increases at the end of May and reaches the peak in its seasonal number at the beginning of June, which coincides in time during both years 2010/2011.

On the basis of the above it can be summarized that the tabanids in Stoyan Zaimovo locality become active in the second half of May and fly until mid-September with a maximum in the seasonal number at the beginning of June (Figure 2).

\section{Seasonal abundance of horse flies in Spassovo locality}

The microclimatic and landscape features of Spasovo locality are very different from those in Stoyan Zaimovo locality. The studied biotope is drier, poorer in tree and shrub vegetation with a limited ability to retain the natural moisture, required for the normal development of the larvae and imago. This reflects on the tabanid overall activity in the region which is much lower than that of Stoyan Zaimovo locality (Table 1).

As a result of the field observations in Spasovo locality it was established that the tabanids in the region became active in the second half of May. At the end of May four species ( $H$. distinguenda, T. quatuornotatus, $H$. pluvialis and Ph. graeca) were registered with the dominant species $T$. quatuornotatus and the subdominant $P h$. graeca being among them.
GANEVA D., et al.

Tabanid activity was extremely low (7 specimens/2010, 5 specimens/2011) in June and species diversity was very poor. The main reason for this was the bad weather (rain, wind and temperature $19-20^{\circ} \mathrm{C}$ ) during the field reports in June. Three of the four species, which began flying in May, continued to fly in June 2010. At that time only $H$. pluvialis activity was not reported, but the beginning of the flight of $T$. bromius (3.6) was marked. Only 5 o $T$. quatuornotatus were captured in June 2011 at a daily temperature of $19^{\circ} \mathrm{C}$. This was the only appearance of the species during the year, and at the same time, this was the lowest temperature at which a flight in Spassovo locality was registered.

The tabanid assemblages was represented in July by the populations of 8 species, six of which were new in the assemblage composition (T. tergestinus, T. unifaciatus, $T$. maculicornis, $T$. spodopterus ponticus, $T$. sudeticus and T. tinctus). The dominant species $T$. tergestinus was the highest in number during both years. Second, by number, was $T$. bromius, but only during the 2010 flight season. The species T. maculicornis, $T$. spodopterus ponticus and T. sudeticus, which appeared for the first time in July 2011 were recorded only once for the whole period of the survey. The highest tabanid activity during the two years of the survey and the highest species diversity ( 8 species) were established in this biotope in July. Out of these 8 species only the species $T$. bromius, $T$. tergestinus and $T$. unifaciatus were active in both years, but with different numbers.

The species $T$. bromus, T. teirgestinus, $T$. tinctus and $T$. unifaciatus continued to fly in August. The diversity of the tabanid assemblage in August increased only with the late summer species $T$. exclusus. The number of captured specimens of T. exclusus was the highest in the 2011 samples. At the same time (August 2011) higher activity was reported for the estival species T.tinctus and for the species $T$. bromius which was active throughout the season. Again, differences in the species composition and the number of captured specimens during the two years sampling were established. Three specimens of 2 species were caught in August 2010 and 25 specimens of 4 species were captured in 2011. The different tabanid activity at one and the same time during both years was due to the peculiarities of the weather conditions during the collection time. The extremely low tabanid activity in August 2010 was caused by high daily 
temperatures (over $32^{\circ} \mathrm{C}$ ), followed by a summer storm, and the significantly higher activity at the same time in 2011 was influenced by the quiet and clear weather with daily temperatures ranging between 24 and $32^{\circ} \mathrm{C}$. The 25 specimens, captured in this biotope on 8.8.2011, represent the largest number of tabanids, captured in August in the localities explored. At the same time, these were the last registered flies in Spasovo locality for 2011 .

During the observation, carried out in the first half of September (10.9.) tabanid activity was not registered despite the appropriate weather conditions (sunny and quiet weather at $27^{\circ} \mathrm{C}$ ). Based on the results of study it can be
GANEVA D., et al. summarized that tabanids in Spasovo locality became active in the second half of May and fly at the latest until the first decade of September. The graphical representation of the tabanid seasonal activity in Spasovo area, both by years (Figure 3) and the study period (Figure 4), represents a unimodal curve with a well-marked peak in the first half of July (5.7.11.7.). The highest activity during this period was established for the dominant species $T$. tergestinus, whose population had the highest number during both years of the study (Table 1). The peak in tabanid seasonal abundance in Spasovo coincides with the peak of seasonal number of T. tergestinus (the first half of July) in this biotope.

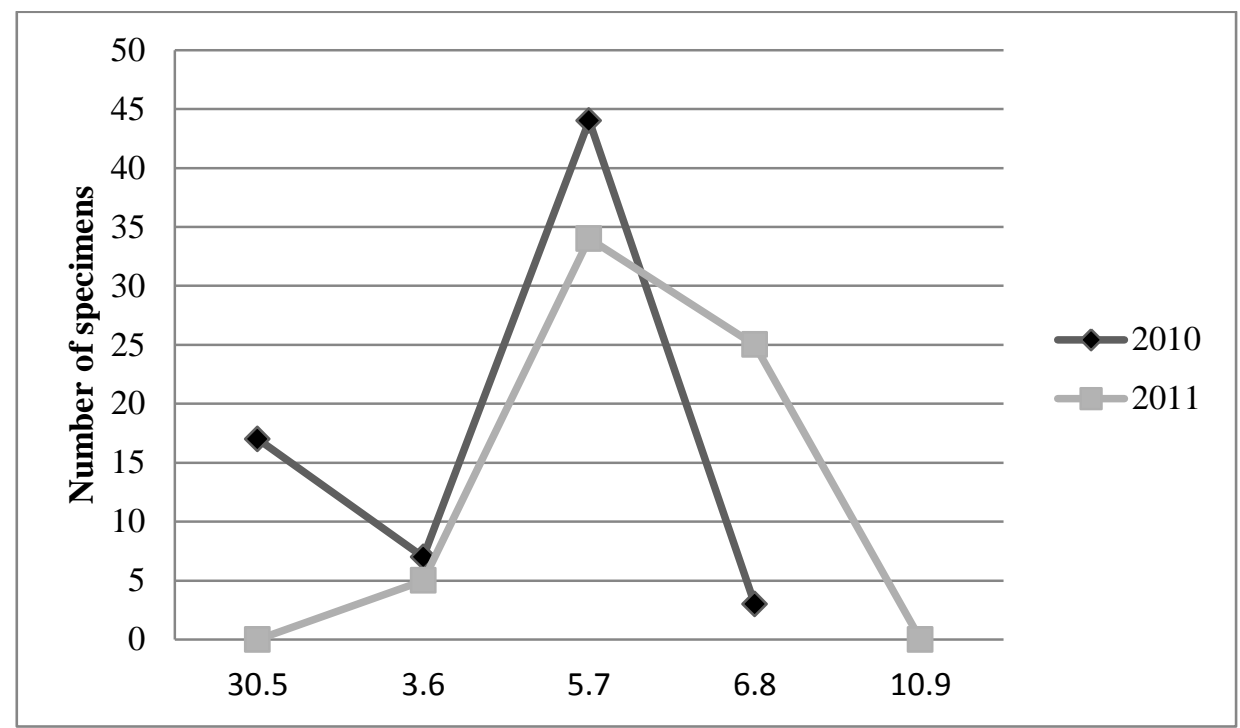

Figure 3. Seasonal abundance of tabanids in the locality Spassovo (2010-2011)

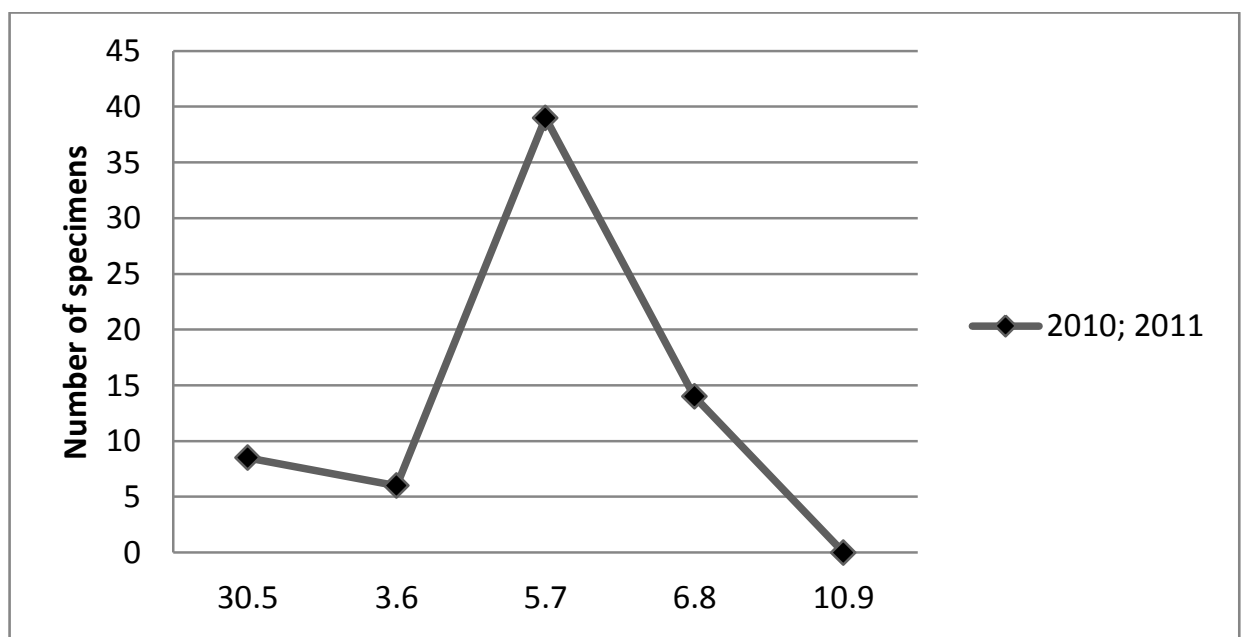

Figure 4. Seasonal abundance of tabanids in the locality Spassovo (average data)

T. bromius (2010), T. maculicornis and $T$. tinctus (2011) show a high activity during the peak in the tabanid seasonal abundance in the area. The remaining species were represented by single specimens. 


\section{CONCLUSION}

Summarized data from biannual observations on tabanids on the territory of the Chirpan Eminences show that under appropriate weather conditions tabanids in the area become active during the second half of May and fly to mid-September with a peak in the seasonal abundance during the first half of July.

T. quatuornotatus, $T$. tergestinus and $P h$. graeca were the dominant species in the area and $T$. tergestinus population was the most numerous in the peak of tabanid seasonal abundance (early July).

In a seasonal aspect a change of the most common species in the tabanid assemblages on the Chirpan Eminences was established. The basic composition of the tabanid assemblages in May and June was determined by the early summer species T. quatuornotatus and summer species $H$. distinguenda and $P h$. graeca, in July - by the polyseasonal ones $T$. tergestinus and $T$. bromius and summer species $T$. maculicornis, $T$. spodopterus ponticus and $T$. tinctus and in August by the summer species $T$. tinctus and late summer species A. loewianus and T. exclusus.

\section{REFERENCES}

1. Chvála, M., Lyneborg, L. and Moucha, J., The Horse Flies of Europe (Diptera, Tabanidae). Entomol Soc of Copenhagen, Copenhagen, 1972.

2.Olsufjev, N., Familly Tabanidae. In: Skarlato O, (ed). Fauna SSSR. Insecta, Diptera. Leningrad, 7 (2), pp 1-434, 1977. (In Russian)

3. Terteryan, A., Rhytms of seasonal and daily activity of horseflies in different vertical zones of the Transcaucasus and the northern slopes of the Bolshovo Kakazsky mountain ridge. Zool Papers, 19: 5-48, 1983. (In Russian)

4. Hackenberger, B.K., Jaric, D. and Krcmar, S., Distribution of tabanids (Diptera: Tabanidae) along a two-sided altitudinal transect. Environ Entomol, 38: 1600-1607, 2009.

5. Baldacchino, F., Porciani, A., Bernard, C. and Jay-Robert, P., Spatial and temporal distribution of Tabanidae in the Pyrenees Mountains: the influence of altitude and landscape structure. B Entomol Res, 104: 1$11,2013$.
GANEVA D., et al.

6. Auroi, Ch., Les Tabanidae (Diptera) de la Tourbiele du Cachot (Jura Neucatelois). II. Phenologie et abundance annuele. B Soc Neuch Sc Nat, 106: 61-71, 1983.

7. Auroi, Ch., Modele de preduction du nombre de captures de Haematopota pluvialis (L.) (Dipt. Tabanidae) d'apres la date et les conditions meteorologiques en plaine et en montagne. Acta Oecol, 6 (2): 179-194, 1985.

8. Ganeva, D., Fauna, phenology and activity of blood sucking tabanids (Tabanidae, Diptera) in Stara Zagora Region. $\mathrm{PhD}$, Trakia University, Stara Zagora, Bulgaria, 1-215, 1998. (In Bulgarian English abstract).

9. Ganeva, D. and Penev, L., Structure and diversity of tabanid assemblages from three pastures in South Bulgaria (Diptera, Tabanidae). Studia dipterologica, 9 (2): 743-755, 2002.

10.Altunsoy, F. and Kiliç, A., Seasonal abundance of horse fly (Diptera: Tabanidae) in Western Anatolia. J Entomol Res Soc, 14 (1): 95-105, 2012.

11.Krčmar, S., Seasonal dynamics of horse flies in Eastern Croatia as a part of the Pannonian Plain (Dipera: Tabanidae). Period biol, 101 (3): 221-228, 1999.

12. Krčmar, S., Seasonal abundance of horse flies (Diptera: Tabanidae) from two locations in eastern Croatia. J Vector Ecol, 30: 316-321, 2005.

13. Krüger, R.F. and Krolow, T.K., Seasonal patterns of horse fly richness and abundance in the Pampa biome of southern Brazil. J Vector Ecol, 40 (2): 364-372, 2015.

14. Drensky, P., Blood-sucking flies of fam. Tabanidae (obody) in Bulgaria. Bull Roy Inst Nat Sc., Sofia, 2: 55-128, 1929. (In Bulgarian, German summary)

15.Ganeva, D. and Kalmushka, M., The tabanid fauna (Diptera:Tabanidae) of the Chirpan Eminences (Bulgaria). Entomol Hellenica, 21: 45-53, 2012.

16. Velev, St., Climatic regioning. In: Kopralev I, Jordanova M, Mladenov Ch, (eds), Geography of Bulgaria: Physical geography. Socio-economic geography. Sofia, Bulgaria. ForCom, pp 155-156, 2002. (In Bulgarian, English abstract)

17. Chvála, M., Family Tabanidae. In: SooS A, Papp L (eds), Catalogue of Palaearctic Diptera, Budapest, 5, pp 97-191, 1988. 